\title{
A ONU faz 50 anos: e agora?
}

\section{LUIZ OLAVO BAPTISTA}

$\mathrm{N}$

A LINGUAGEM corrente - e nela quanto vai de esperança - usa-se chamar os 50 anos de meia idade. Na história de homens e mulheres também é a idade do lobo, aquela em que as últimas paixões e loucuras são praticadas, despedida da juventude que já se foi há muito, e aceitação da velhice e da idéia do término.

Isso mesmo, lembram os versos de Dante, "Nel mezzo del cammin di nostra vita / mi ritrovai per una selva oscura. Esta selva selvaggia e aspra e forte". Cinqüenta anos seria o "mezzo del cammin", e a vida, "esta selva selvaggia e aspra e forte" (1).

O seminário que o IEA e o Departamento de Direito Internacional da FDUSP convocaram propôs-se a responder à interrogação de saber se "la dritta via" será "smarrita", para a ONU, que continuará perdida na "selva oscura", ou se esta poderá seguir o seu caminho na encruzilhada dos 50 anos para entrar, ao menos, no Purgatório.

Foi, devo dizer, um interrogativo esperançoso, quase otimista já que os expositores demonstraram, como dizia o Vate, que "temer si deve sole quelle cose c'banno potenza di fare altrui male; dell'altre no, che non sono paurose".

As análises passaram não só pela ONU, organização internacional, como pela instauração de um regime jurídico mais amplo na ordem internacional.

Assim, a temática dos direitos humanos foi abordada por Celso Lafer; a perspectiva brasileira, por Ronaldo Sardenberg; as possibilidades da ONU sob a ótica da dimensão cooperativa, por José Augusto Guilhon de Albuquerque; os mecanismos de segurança coletiva, por Marcos Castrioto de Azambuja; finalmente, o ângulo da reforma da Carta por José Carlos Magalhães e Ramiro Saraiva Guerreiro, este fazendo o balanço das possibilidades, aquele do ângulo jurídico institucional, de uma reforma e de sua necessidade.

É a partir dessas brilhantes análises que estas linhas procuram abordar aspectos novos e alinhavar uma síntese. Partir da história é imprescindível neste caso.

Recordamos que o direito das gentes era forma embrionária que resumia as regras dos tratados entre os soberanos. À comunidade de povos que existia 
sob a Pax Christiana, vimos suceder o advento do Estado-nação, e a Reforma. Veio depois o absolutismo e, com ele, a transferência da soberania dos monarcas para a Nação, ou seja, com a criação do Estado Moderno, delineou-se uma nova estrutura, que refletiu a dicotomia dos direitos nacionais - público e privado.

O direito interno opunha-se ao internacional, e neste o privado ao público. Os direitos nacionais, separados entre si, constituíam um arquipélago.

O anseio da unidade aparece, sem sucesso, em tentativas que se esgotavam ou na criação de alianças ou numa organização internacional, e em curto tempo culminam em fracasso como ocorreu com a Sociedade das Nações. Estava-se num estado de anarquia, no qual a via usual para a solução dos conflitos era a guerra. Por isso se disse que havia um estado da Natureza, da guerra de todos contra todos (2), o paradigma hobbesiano maquiavélico, que a SDN procurava resolver, consagrando a paz como uma aspiração comum da humanidade.

A Carta de São Francisco sucede, como marco histórico dessa evolução, pelo fato de ter sido também uma tentativa de constitucionalização do direito internacional.

Nela foi incluído - ao contrário do que se diz em alguns manuais - o indivíduo entre os sujeitos do direito internacional. O indivíduo aparece sob duplo enfoque - o de objeto de uma declaração que lhe reconhece direitos, e o de sujeito dos direitos -, que caberia a todos, em especial aos Estados Unidos, assegurar na nova organização.

Ao introduzir uma declaração, realmente universal - pelo alcance e pela amplitude - dos direitos do Homem, o ser humano passou a tê-los reconhecidos oficial e formalmente, e a ter o foro no qual a defesa desses direitos passaria a ser assegurada. Não mais como ação do suserano-soberano protegendo o seu súdito - como ocorria antes - mas, sim, de toda a humanidade, atuando em defesa de um semelhante. Daí a proteção dos direitos humanos passa a ser um dever de todos os Estados, e reconhece-se a existência dos crimes contra a humanidade e o dever de respeitar os direitos humanos.

O texto exemplar de Celso Lafer, nesta coletânea, aponta bem esse caráter de direito novo, de esforço de constitucionalização das relações internacionais no que se refere aos direitos humanos, e nada há que se possa acrescentar à sua lúcida análise.

A partir da Carta de S. Francisco - e daí sua importância como elemento de constitucionalização do direito internacional - desenvolveram-se vertentes, novas, não só na definição de direitos, como na implementação e garantia dos mesmos. Os direitos de mulheres, crianças e adolescentes, minorias, foram definidos, e sua defesa foi implementada com sucesso e empenho variável. 
A forma como essa defesa se exerce também evolui. Vai desde o bloqueio da África do Sul pelas nações que integram a ONU - em razão do apartheid que prosseguiu por décadas - até em nossos dias, a confusa atuação na guerra civil que assola a antiga Iugoslávia, passando pela constituição de tribunais internacionais.

A Carta de São Francisco, ademais, liga-se diretamente a outras construções normativas - os acordos de Bretton Woods e a Carta de Havana - e essas servem de base para uma elaboração legislativa internacional como nunca se viu na história da Humanidade. Realmente, sob a inspiração dos princípios da Carta de São Francisco nascem acordos, declarações, resoluções, deliberações, uma pletora de hard e soft law, que cobrem a maioria dos aspectos da vida contemporânea.

A existência de uma constituição politica ao lado de constituições econômicocomerciais, também abriu o espaço para modelos jurídicos elaborados pela comunidade dos comerciantes internacionais, pela banca internacional, e pelas empresas transnacionais.

Como lembrava Rigaux, os acordos TOVALOP e CRISTAL cuidaram de regular as responsabilidades de transportadores e produtores de petróleo face aos Estados, pelos danos que suas atuações causarem, como se fossem tratados internacionais, inclusive com a criação de organismos sui-generis para regê-los. Condições gerais e mecanismos arbitrais garantem segurança jurídica ao comércio exterior, associados a usos e costumes, formando um corpo de regras objetivas (3) que enquadram o comércio internacional. Tão orgânica foi essa elaboração que se chegou a falar em nova lex mercatoria.

Normas técnicas nasceram de resoluções de organismo ligado à ONU e são aplicadas sem discussão. A OMS regula a publicidade dos sucedâneos do leite materno. Enfim os exemplos estão em toda a parte.

A tal ponto ocorreu essa evolução que a tradicional polêmica monistas versus dualistas já foi colocada na estante dos momentos históricos passados e a concepção pluralista (4) reina, até que outra a venha suceder. Admite-se que há, não uma, mas, várias ordens jurídicas, entrosadas ou coordenadas, cada qual com seu âmbito de aplicação.

Ao mesmo tempo, as ONGs (as verdadeiras, não as associações civis que visam a promover pessoas) vão atuando para suprir aquilo que não pode ser feito pelo indivíduo isolado ou pelas organizações intergovernamentais. Tanto a defesa do meio ambiente, o direito de minorias étnicas ou religiosas, quanto a oposição a experimentos nucleares têm sido objeto da ação dessas organizações, que por essa forma complementam a ONU.

Como pode surgir tudo isto? Porque a estrutura jurídica criada a partir da Carta de São Francisco criou as fundações para esse fim. 
Dessa forma, limitar a comemoração - e a análise crítica dos 50 anos da Carta à vida de sua criatura direta, a ONU - é diminuir o alcance real da Carta.

\section{A problemática da segurança coletiva}

Entretanto, se no campo da constitucionalização do direito internacional encontramos alvo para o nosso otimismo, ao ler os jornais que relembravam os 50 anos de Hiroshima e suas tintas de racismo, "la vista che m'apparve d'un leone", foram as experiências nucleares no atol de Muroroa. Mas "una lupa, che di tutte brame / sembiava carca nella sua magrezza ... questa mi porse di tanta gravezza / con la paura ch'uscia di sua vista", o furor genocida dos Cárpatos. Isto é, a ONU apesar de tudo não erradicou o mal.

Como tratou a ONU do problema da segurança neste meio século?

José Augusto Guilhon de Albuquerque, Ramiro Saraiva Gusmão e Marcos Castrioto de Azambuja abordaram o problema.

Guilhon, pelo exame da dimensão cooperativa que permitiu superar a polarização da Guerra Fria. Sua análise demonstra como o crescimento da ONU, como estrutura organizacional, foi pouco a pouco segmentando os temas, permitindo o debate de cada um separadamente, impedindo com isso que a polarização global redundasse em um não-diálogo. Faz-lhe eco a exposição do Embaixador Saraiva Guerreiro, mostrando que, na ONU, "realizou-se a pré-condição para o funcionamento da organização internacional, isto é, a possibilidade de consenso, senão total ou permanente, freqüente e operacional entre os membros do Conselho de Segurança”.

Marcos de Azambuja contemplou a instabilidade estável, que cerca o conceito de segurança coletiva na ONU como o Conselho de Segurança, o qual conseguiu - apesar do mecanismo do veto - desempenhar um papel de foro de debates, câmara de descompressão e sua importância. A Assembléia Geral cresceu e passou a desempenhar papel maior que os autores da Carta de São Francisco haviam previsto, ocupando espaços que o Conselho não podia ou não conseguia preencher. Tal como um organismo supre as áreas danificadas por uma isquemia, fazendo com que outras assumam as funções dessas, assim também a Assembléia Geral procurou suprir a paralisia em que o poder de veto dos quatro grandes atirava o Conselho de Segurança.

Na sua brilhante análise, o embaixador Azambuja recorda como as armas nucleares - o aterrador leone, na imagem que emprestamos de Dante - representaram "um revolucionário reexame da própria equação de custo benefício de enfrentamentos bélicos entre seus detentores" (5). 
A reação que a maioria dos países e da opinião pública internacional opuseram aos experimentos nucleares franceses, assim como a ação, violenta, no Kuwait, e desajeitada embora, da ONU na Bósnia e na Croácia, são a prova de que, bem ou mal, temos mecanismos de segurança coletiva - e, sobretudo de que como se disse "os antigos conceitos ferramentas das Nações Unidas requerem um urgente e extenso aggiornamento" (6).

Ao que tudo indica, esse aggiornamento passa por uma volta - ainda que parcial - ás origens, ou seja a uma releitura da Carta de São Francisco e seus princípios, pois como lembra o embaixador Marcos de Azambuja, "quase todas as premissas que levaram à criação da ONU se confirmaram bem além do que poderiam ter antecipado os seus founding fathers".

\section{As perspectivas brasileiras face à ONU}

Ao enfocarmos a ONU, sob uma perspectiva brasileira - objeto da conferência do ministro Ronaldo Sardenberg, da Secretaria de Assuntos Estratégicos -, vemos a preocupação do Brasil com o aperfeiçoamento da Organização. Essa é uma atitude em que governo e povo coincidem.

Pouca gente sabe, mas no corpo de voluntários da ONU - aqueles funcionários que carregam pedras e desempenham missões difíceis em lugares pouco turísticos - há grande número de brasileiros. São, proporcionalmente, dos maiores contingentes nacionais. Ao contrário, nos postos de direção e superiores, somos francamente minoritários, tanto em números absolutos como relativos.

O que se pode deduzir daí é que o povo brasileiro valoriza o que é importante na ONU - solidariedade e humanismo - e por isso mesmo procura contribuir para esses objetivos. Mas, por outro lado, o Estado brasileiro não deu, historicamente, muita importância à sua participação na estrutura da ONU; aliás, dos poucos cargos importantes atribuídos a brasileiros, parte foi utilizada por diplomatas aposentados ou em fim de carreira, o que parece inadequado. Só recentemente passou-se a perseguir, com interesse ativo, uma participação nos quadros da Organização e na elaboração da sua reforma, em especial no que se refere ao Conselho de Segurança.

A recente postulação de um cargo no Conselho de Segurança é, sem dúvida, mudança significativa nessa política. Entretanto, não deve o esforço do país parar por aí: a presença de brasileiros em funções superiores será facilitadora do diálogo, um estímulo à participação na ONU.

Essas perspectivas mesclam-se com a idéia de reforma.

Descreve-as com o conhecimento de quem viveu a Organização, inclusive representando o país no Conselho de Segurança, o embaixador Sardenberg, 
delineando a agenda brasileira para a ONU, e mostrando os pontos críticos e os caminhos para eliminar os aspectos negativos. O embaixador Saraiva Guerreiro também fala na reforma da ONU, propondo pontos para nela serem equacionados, no campo da segurança coletiva.

Não se reforma uma instituição falida - fecha-se. Por isso, pode-se dizer que quando todos os expositores do Seminário, objeto desta publicação, de alguma forma falaram sobre a reforma da ONU - inclusive como o fez, com a habitual competência, o meu caro amigo José Carlos de Magalhães, detalhando propostas e possibilidades - podemos ter certeza de que ela sobreviveu como Organização, ainda que não corresponda aos ideais da maioria.

\section{Concluindo}

As perspectivas da ONU continuam a ser, como de há muito, difusas. Não diria turvas, nem pessimistas, mas sim difusas. Esse flou decorre justamente do caráter assemblear da Organização. Nenhuma atuação se faz sem razoável consenso, nenhuma atitude se toma sem negociação. As operações de paz são a demonstração disso.

No caso das últimas operações de paz da ONU repete-se o que ocorreu nas demais. Diante dos reféns tomados na Guerra da Croácia, podemos recordar as mortes do Conde Bernardotte, de Dag Hamarskjoeldt e de muitos outros. Não há que se ter ilusões: missões de paz são difíceis, e quem vai apartar brigas, diz o ditado, sai machucado. É justamente pela consciência da dificuldade, após a avaliação dos erros cometidos, que se poderá construir uma doutrina a esse propósito.

Outro ponto em que se contempla a ação da ONU refere-se ao processo de desenvolvimento. $\mathrm{O}$ abandono das teses da nova ordem econômica internacional, associado ao incremento da fome, da miséria e da pobreza nos países periféricos têm sido debitados à sua omissão. Entretanto a ação da FAO, da UNICEF, da ACNUR, e de muitas outras instituições do sistema das Nações Unidas tem sido o único fator de alívio num mundo em que reina a indiferença, como bem apontou Guilherme Cunha em suas palavras na abertura do Colóquio.

As conferências internacionais, como lembrou Ronaldo Sardenberg, permitiram que "três medidas práticas e interligadas estejam sendo operacionalizadas". São elas a implantação do resultado das grandes conferências desta década, inauguradas com a do Rio sobre o meio ambiente; a ampliação do conceito de desenvolvimento sustentável para os planos social, tecnológico e financeiro; e, por último, a idéia de convocar novamente a conferência mundial do desenvolvimento. A elas devemos acrescentar a OMC e o GATT-94.

Na realidade, a Carta de São Francisco nos permitiu desenvolver conceitos novos como o desenvolvimento sustentado, o patrimônio comum da humanidade, 
o direito a um meio ambiente reservado, todos eles frutos de conferências internacionais, assim como sustentar meio século sem grandes conflitos armados e um vasto processo legislativo no plano internacional. São notas positivas no balanço destes 50 anos da Carta.

Esperemos que a humanidade possa achar um Virgílio que, apelando para a solidariedade e a racionalidade, lembre-a de que "convien tenere un altro viaggio", na direção da construção de uma ordem internacional que "non ciberà terra nè peltro, / ma sapienza, amore e virtute".

Notas

1 Todas as citações da Divina Commedia são do Canto Primo, Proemio, $21^{a}$ ed. completa. Milano, Ed. Ulrico Hoepli, 1988.

2 Cf. exposição de Celso Lafer, neste número.

3 Cf. Michael J. Bonnel. Le regolle oggetive nel commercio internazionale: clausole tipiche e condizione generali. Milano, Giuffre, 1976.

4 V. François Rigaux. Droit public et droit privé dans les relations internationales. Paris, Pedone, 1977.

5 Cf. Marcos de Azambuja, exposição neste número.

6 Id. ibid.

Luiz Olavo Baptista é professor da Faculdade de Direito da UsP, onde também é chefe do Departamento de Direito Internacional.

Palestra feita pelo autor no Colóquio Carta de São Francisco: 50 anos depois, organizado pela Área de Assuntos Internacionais do Instituto de Estudos Avançados na Sala do Conselho Universitário da USP no dia 23 de junho de 1995. 